\title{
Effects of Exchanging Battery on the Electric Vehicle's Electricity Consumption in a Single-Lane Traffic System
}

\author{
Shi-Chun Yang, ${ }^{1}$ Wen-Zhuang Gou, ${ }^{1}$ Tie-Qiao Tang, ${ }^{1}$ and Hua-Yan Shang ${ }^{2}$ \\ ${ }^{1}$ School of Transportation Science and Engineering, Beihang University, Beijing 100191, China \\ ${ }^{2}$ Information College, Capital University of Economics and Business, Beijing 100070, China \\ Correspondence should be addressed to Tie-Qiao Tang; tieqiaotang@buaa.edu.cn
}

Received 9 May 2014; Revised 11 August 2014; Accepted 13 August 2014; Published 30 October 2014

Academic Editor: Yongkun Li

Copyright (C) 2014 Shi-Chun Yang et al. This is an open access article distributed under the Creative Commons Attribution License, which permits unrestricted use, distribution, and reproduction in any medium, provided the original work is properly cited.

\begin{abstract}
We propose a car-following model to explore the influences of exchanging battery on each vehicle's electricity consumption under three traffic situations from the numerical perspective. The numerical results show that exchanging battery will destroy the stability of traffic flow, but the effects are related to each vehicle's initial headway, the time that each electric vehicle exchanges the battery, the proportion of the electric vehicles that should exchange the battery, the number of charging stations, and the distance between two adjacent charging stations.
\end{abstract}

\section{Introduction}

Recently, traffic energy consumption and pollution have turned very serious and attracted researchers to develop various models to explore the vehicle's fuel consumption and emissions [1-9]. Although the models can describe some mechanisms of the vehicle's fuel consumption and exhaust emissions, the traffic pollution cannot completely be eliminated since the traditional vehicles need to consume oil and will produce exhaust emissions. To reduce the vehicle's exhaust emissions, engineers designed the electric vehicles without exhaust emissions [10-15]. With the development of the electric vehicles, researchers proposed some models to study the electric vehicle's electricity consumption under some specific conditions [16-18], but they do not study the influences of exchanging battery at the charging station on the electric vehicle's electricity consumption. In this paper, we use the car-following model [17] to explore the influences of exchanging battery at the charging station on the electric vehicle's consumption.

\section{Numerical Tests}

In this section, we study the influences of exchanging battery at the charging station on each electric vehicle's electricity consumption. Before studying the effects, we should give the following assumptions.

(1) There are $M$ on-line charging stations, where their positions are, respectively, $x_{10}, x_{20}, \ldots, x_{M 0}$ (see Figure 1).

(2) All $N$ vehicles are electric vehicles, where $N$ is the number of vehicles; the proportion that the vehicle should exchange its battery at the charging station is $r$.

(3) All the drivers are homogeneous.

(4) The road is a ring and its length is $L$.

(5) When an electric vehicle should charge electricity at the charging station, the driver will choose to exchange the battery, since the charging time is relatively long.

(6) At each charging station, only a vehicle can exchange the battery every time and there are enough batteries.

(7) Each vehicle's initial headway is $\Delta x_{0}$.

(8) The time that each driver exchanges the battery is $T_{0}$.

Based on the aforementioned assumptions, the $n$th electric vehicle's driving behavior can be decomposed as in the following five parts. 


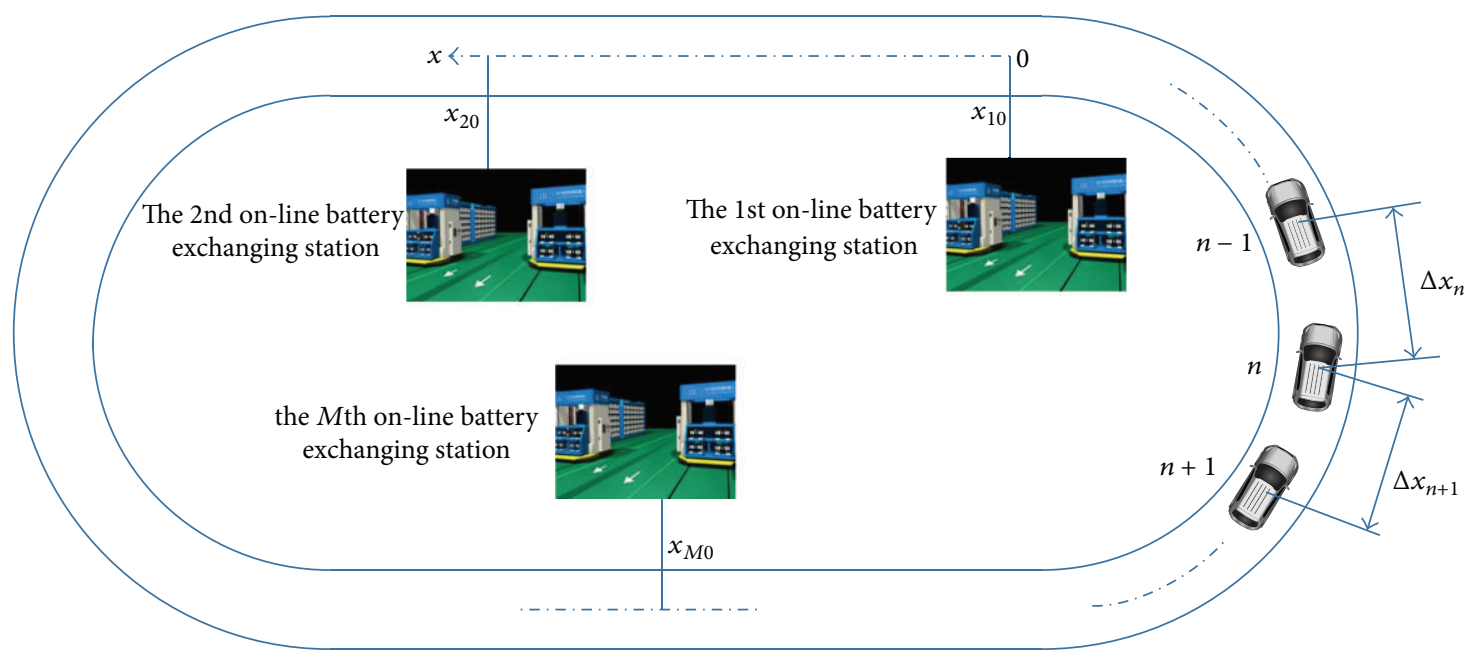

FIGURE 1: The car-following model for electric vehicle on a road with on-line charging stations.

(a) Before the $(n-1)$ th vehicle arrives at a charging station or after the $n$th vehicle leaves the charging station, the $n$th vehicle's acceleration can be formulated as follows:

$$
\frac{\mathrm{d} v_{n}}{\mathrm{~d} t}=\alpha\left(V\left(\Delta x_{n}\right)-v_{n}\right)+\lambda \Delta v_{n}
$$

where $\alpha, \lambda$ are reaction coefficients and $v_{n}, V\left(\Delta x_{n}\right), \Delta x_{n}$, and $\Delta v_{n}$ are, respectively, the $n$th vehicle's speed, optimal speed, headway, and relative speed.

(b) When the $(n-1)$ th vehicle is running forward to one charging station, the $n$th vehicle's acceleration can be formulated as follows:

$$
\frac{\mathrm{d} v_{n}}{\mathrm{~d} t}=\alpha\left(V\left(\Delta x_{n}\right)-v_{n}\right)+\lambda\left(1-p_{n-1}\right) \Delta v_{n}+\mu p_{n-1}\left(-v_{n}\right),
$$

where $\mu$ is a reaction coefficient and $p_{n-1}$ is the probability that the $(n-1)$ th electric vehicle stops to exchange battery at the charging station.

(c) When the $(n-1)$ th vehicle leaves a charging station and if the $n$th vehicle should exchange its battery at the charging station, the $n$th vehicle will adjust its acceleration; that is, before the $n$th vehicle gets to the charging station, its acceleration can be reduced formulated as follows:

$$
\frac{\mathrm{d} v_{n}}{\mathrm{~d} t}=\alpha\left(V\left(\Delta \bar{x}_{n}\right)-v_{n}\right)+\mu\left(-v_{n}\right),
$$

where $\Delta \bar{x}_{n}=x_{0}-x_{n}$ is the spatial distance between the $n$th vehicle and the charging station (here $x_{0}$ is the charging station's position and $x_{n}$ is the $n$th vehicle's position).

(d) During the whole process where the driver exchanges the battery at a charging station, the $n$th vehicle's motion equation can be formulated as follows:

$$
v_{n}=0, \quad \frac{\mathrm{d} v_{n}}{\mathrm{~d} t}=0 .
$$

(e) After the $n$th vehicle's driver exchanges the battery, this vehicle will immediately restart and its acceleration can be described by (1a).
In real traffic system, $p_{n-1}$ is related to two factors, where one is the time that the $(n-1)$ th driver gets to a charging station (at this charging state, the $(n-1)$ th driver should exchange the battery) and the other is the time of exchanging battery. Thus, we can define $p_{n-1}$ as follows:

$$
p_{n-1}(t)= \begin{cases}1, & \text { if } t_{0}<t \leq t_{0}+T_{0} \\ 0, & \text { otherwise, }\end{cases}
$$

where $t_{0}$ is the time that the $(n-1)$ th driver reaches the charging station.

Although there may be quantitative differences between the electric vehicle's optimal speed and the traditional vehicle's optimal speed, there are no qualitative differences between the two optimal speeds. Therefore, we can for simplicity define the optimal speed in (1a), (1b), (1c), and (1d) as follows [19]:

$$
V\left(\Delta x_{n}\right)=V_{1}+V_{2} \tanh \left(C_{1}\left(\Delta x_{n}-l_{c}\right)-C_{2}\right),
$$

where $V_{1}=6.75 \mathrm{~m} / \mathrm{s}, V_{2}=7.91 \mathrm{~m} / \mathrm{s}, C_{1}=0.13 \mathrm{~m}^{-1}$, and $C_{2}=1.57$ are four parameters and $l_{c}=5 \mathrm{~m}$ is the vehicle's length.

It is difficult to use (1a), (1b), (1c), and (1d) to study the effects of exchanging battery on each vehicle's electricity consumption from the analytical perspective, so we should here apply numerical scheme to discretize (1a), (1b), (1c), and (1d). There are many numerical schemes to discretize (1a), (1b), (1c), and (1d), but the numerical schemes have no qualitative effects on the following numerical results; in addition, the main aim of this paper is to study the qualitative effects of exchanging battery on each electric vehicle's electricity consumption in a single-lane traffic system. Therefore, we can here use the Euler difference scheme in the following numerical tests; that is,

$$
\begin{gathered}
v_{n}(t+\Delta t)=v_{n}(t)+\frac{\mathrm{d} v_{n}(t)}{\mathrm{d} t} \Delta t, \\
x_{n}(t+\Delta t)=x_{n}(t)+v_{n}(t) \Delta t+\frac{1}{2} \frac{\mathrm{d} v_{n}(t)}{\mathrm{d} t}(\Delta t)^{2},
\end{gathered}
$$


where $\Delta t=0.05 \mathrm{~s}$ is the time-step length. Other parameters are defined as follows [20]:

$$
\alpha=0.41, \quad \lambda=0.2, \quad \mu=0.3 .
$$

Before studying the influences of exchanging battery on the electric vehicle's electricity consumption, we should introduce some models that are used to study the electric vehicle's electricity consumption. Mehrdad et al. [21] proposed a model to study the output power of the electric vehicle's battery, where the output power of the $n$th vehicle's battery can be written as follows:

$$
P_{\mathrm{b}-\text { out }}=\frac{v_{n}}{\eta_{\mathrm{te}} \eta_{m}}\left(\delta m \frac{\mathrm{d} v_{n}}{\mathrm{~d} t}+m g(f+i)+\frac{\rho C_{D} A}{2} v_{n}^{2}\right),
$$

where $P_{\mathrm{b}-\text { out }}$ is the battery's output power; $\delta$ is the coefficient related to the vehicle's mass; $f$ is the rolling resistance coefficient; $i$ is the grade coefficient; $C_{D}$ is the aerodynamic drag coefficient; $\rho$ is the air density; $g$ is the gravity acceleration; $m, A, \eta_{\mathrm{te}}$ are, respectively, the vehicle's mass, frontal area, and transmission efficiency; and $\eta_{m}$ is the motor efficiency.

Since each electric vehicle can partly recover the braking energy and restore it into the battery, we obtain the $n$th vehicle's regenerative braking power based on (6); that is,

$$
P_{\mathrm{b}-\text { in }}=k v_{n} \eta_{\mathrm{te}} \eta_{m}\left(\delta m \frac{\mathrm{d} v_{n}}{\mathrm{~d} t}+m g(f+i)+\frac{\rho C_{D} A}{2} v_{n}^{2}\right),
$$

where $k(0<k<1)$ is the percentage of the total braking energy that can be recovered by the motor. In real traffic system, $k$ is a function of the property of the electric vehicle's braking, the battery property, and other related factors.

In this paper, we do not use (6) and (7) to study the vehicle's electricity consumption, since they consider too many factors. Since (6) shows that the vehicle's some electricity is consumed by its resistance, we should use the parameter $\eta_{e}$ to substitute the parameter $\eta_{m}$, where $\eta_{e}$ is the battery's driving efficiency and $\eta_{e}<\eta_{m}$. The electricity consumed by other accessories (e.g., the electric power steering) is not considered and the electricity consumption may be relatively higher, so we should consider the influences of the accessories on the vehicle's electricity consumption. Thus, we should here rewrite (6) as follows:

$$
P_{\text {total }}=\frac{v_{n}}{\eta_{\mathrm{te}} \eta_{e}}\left(\delta m \frac{\mathrm{d} v_{n}}{\mathrm{~d} t}+m g(f+i)+\frac{\rho C_{D} A}{2} v_{n}^{2}\right)+P_{\text {accessory }}
$$

and (7) can be rewritten as follows:

$$
\begin{aligned}
P_{\text {total }}= & k v_{n} \eta_{\mathrm{te}} \eta_{e}\left(\delta m \frac{\mathrm{d} v_{n}}{\mathrm{~d} t}+m g(f+i)+\frac{\rho C_{D} A}{2} v_{n}^{2}\right) \\
& +P_{\text {accessory }},
\end{aligned}
$$

where $P_{\text {total }}$ is the battery's total power.

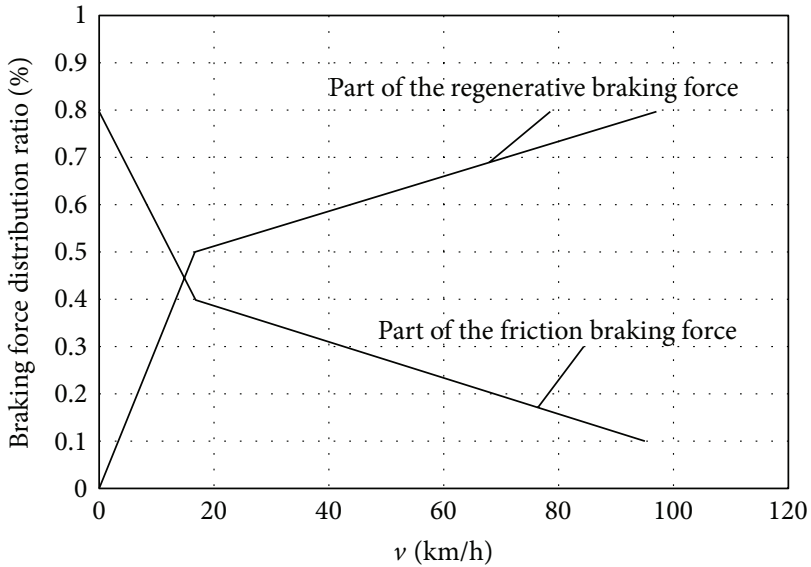

FIgURE 2: The distribution of the braking force in ADVISOR [22].

TABLE 1: The values of the vehicle's related parameters.

\begin{tabular}{lc}
\hline$\delta$ & 1.1 \\
$m$ & 1500 \\
$f$ & 0.015 \\
$C_{D}$ & 0.3 \\
$A$ & 1.8 \\
$\rho$ & 1.2 \\
$\eta_{\text {te }}$ & 0.85 \\
$\eta_{e}$ & 0.85 \\
$P_{\text {accessory }}$ & 1000 \\
$U$ & 300 \\
$I$ & 100 \\
\hline
\end{tabular}

Using the relationship between the power and energy, the vehicle's electricity consumption can be defined as follows:

$$
W=P_{\text {total }} \cdot t,
$$

where $W$ is the electric vehicle's electricity consumption.

In real traffic system, the parameter $k$ is very complex and is related to many factors (e.g., speed, acceleration, etc.), but it is directly related to the regenerative braking force (see Figure 2) [22]. Thus, based on Figure 2, here we define $k$ as follows:

$$
k= \begin{cases}0.5 * \frac{v_{n}}{5} & \text { if } v_{n}<5 \mathrm{~m} / \mathrm{s} \\ 0.5+0.3 \frac{v_{n}-5}{20} & \text { otherwise. }\end{cases}
$$

And other related parameters' values are shown in Table 1.

In this paper, we use three typical situations to explore the effects of exchanging battery on the vehicle's electricity consumption (note: the main aim of this paper is to study the influences of exchanging battery on each electric vehicle's electricity in a single-lane traffic system, so we do not explore the shock wave, travelling wave, and other traffic phenomena 


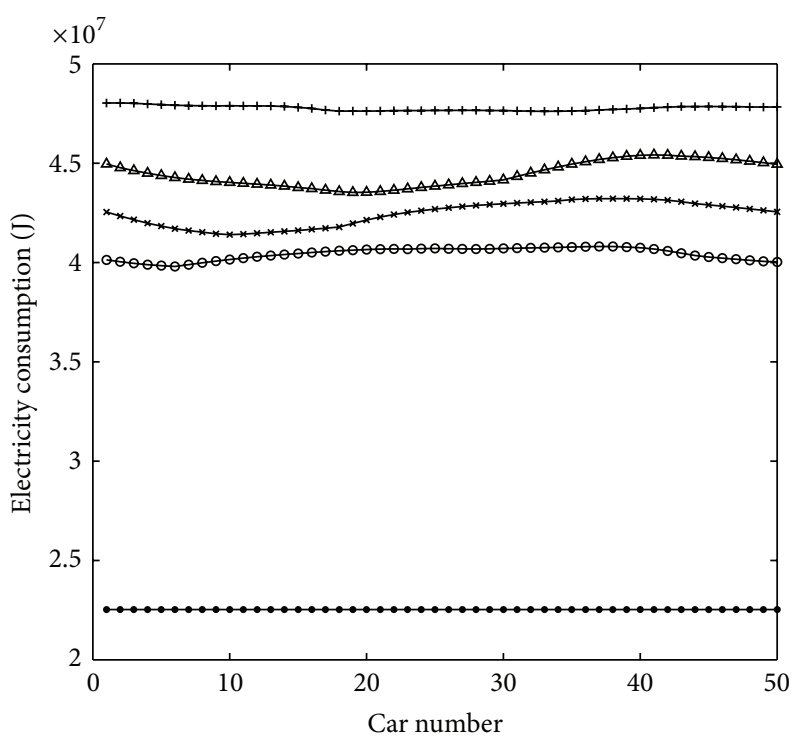

(a)

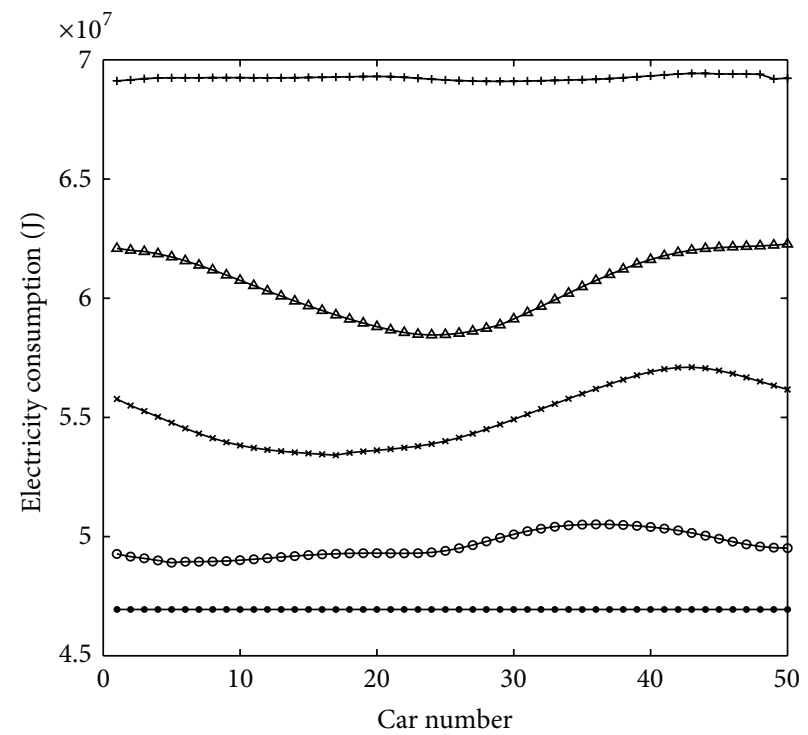

(b)

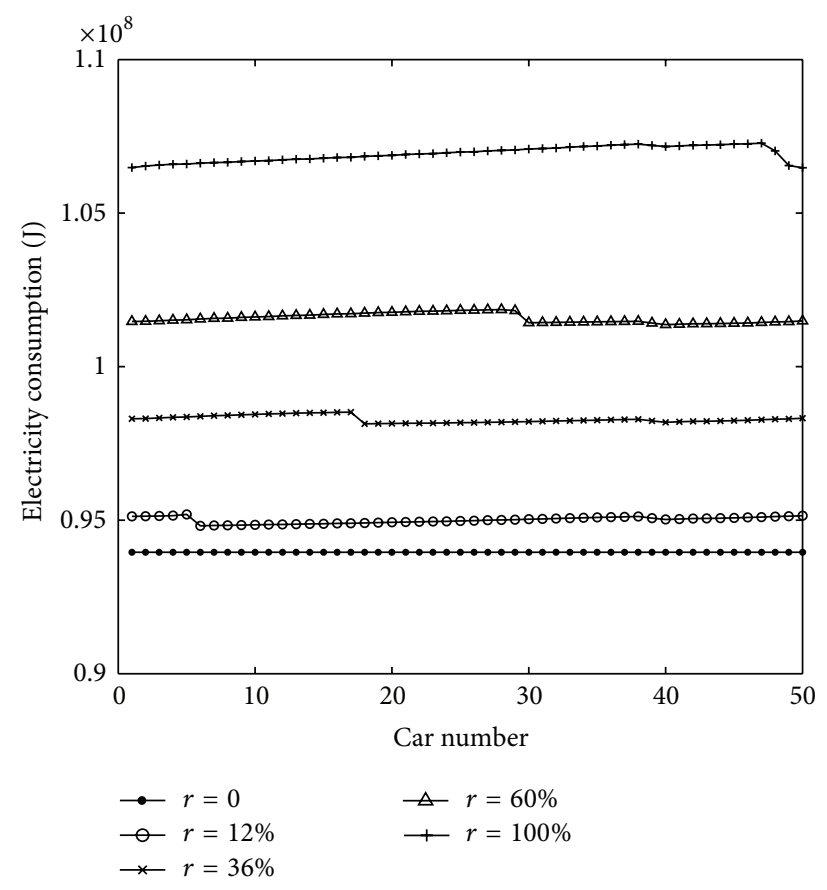

(c)

FIgURE 3: The total electricity consumed by each vehicle under $T_{0}=120 \mathrm{~s}$, where (a) $\Delta x_{0}=20 \mathrm{~m}$, (b) $\Delta x_{0}=40 \mathrm{~m}$, and (c) $\Delta x_{0}=80 \mathrm{~m}$.

resulted by exchanging battery in this paper); that is, consider the following.

\section{Case I. There exists one charging station.}

Case II. There exist two charging stations, where the spatial distance between the two adjacent charging stations is 300 meters.

Case III. There exist two charging stations, where the spatial distance is 500 meters.
2.1. Case I. Firstly, we study the effects of exchanging battery on each vehicle's electricity consumption under different $\Delta x_{0}$ (see Figure 3). From this figure, we can conclude the following results.

(1) Exchanging the battery at the charging station will enhance each vehicle's electricity consumption.

(2) Under the same $\Delta x_{0}$, the increments increase with $r$.

(3) Under the same $r$, the increments increase with $\Delta x_{0}$. 


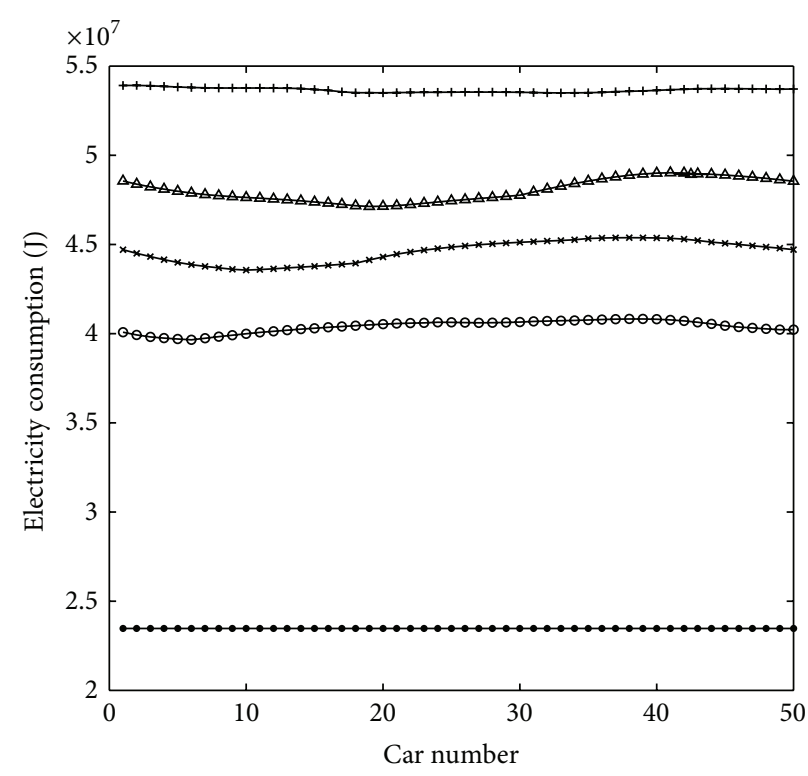

(a)

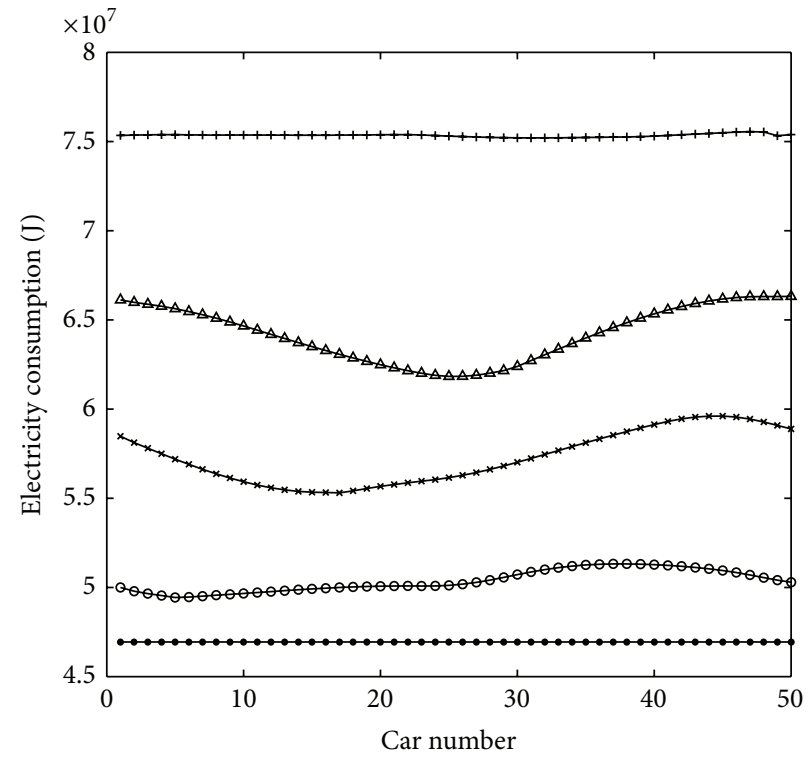

(b)

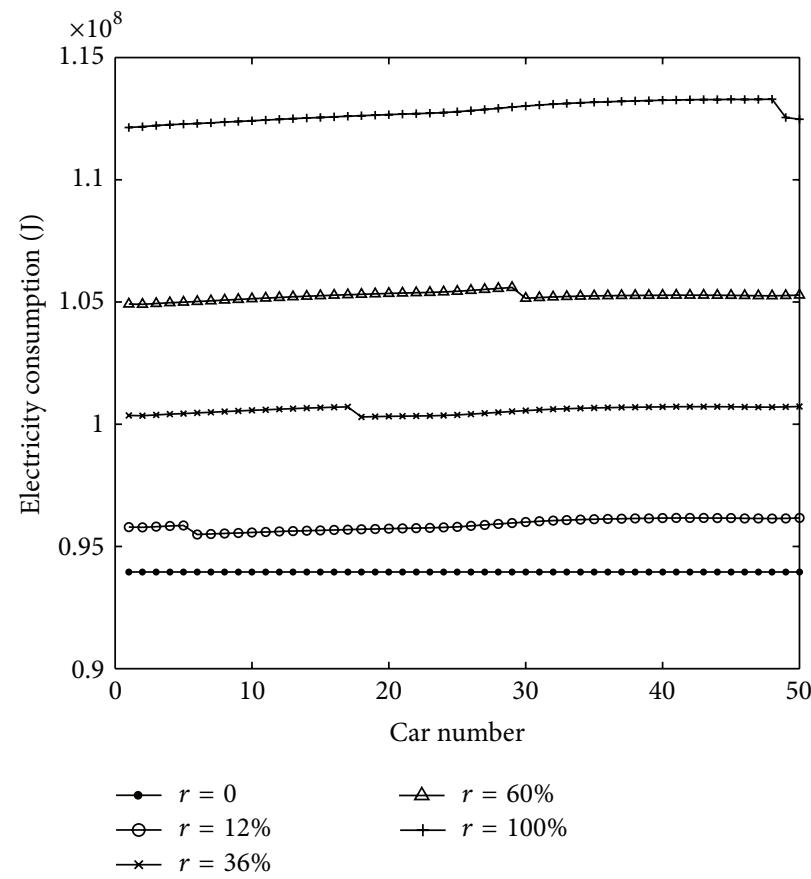

(c)

FIgURE 4: The total electricity consumed by each vehicle under $T_{0}=240 \mathrm{~s}$, where (a) $\Delta x_{0}=20 \mathrm{~m}$, (b) $\Delta x_{0}=40 \mathrm{~m}$, and (c) $\Delta x_{0}=80 \mathrm{~m}$.

Next, we study the impacts of exchanging battery on each vehicle's electricity consumption under different $T_{0}$ (see Figure 4). Combining with Figure 3, we find that under the same $\Delta x_{0}$, the increments increase with $T_{0}$.

Finally, we study all of the vehicles' total electricity consumption under the above two situations (see Figure 5). From this figure, we have the following.

(I) The total electricity consumption increases with $r$.

(II) Under the same $\Delta x_{0}$, the total electricity consumption increases with $T_{0}$.
(III) Under the same $T_{0}$, the total electricity consumption increases with $\Delta x_{0}$.

2.2. Case II. In this subsection, we explore the effects of the number of charging stations on each vehicle's electricity consumption, where other parameters are the same as those used in Case I. The numerical results are shown in Figure 6. From Figure 6, we can see the following.

(1) Figure 6 is qualitatively similar to Figure 3 . 


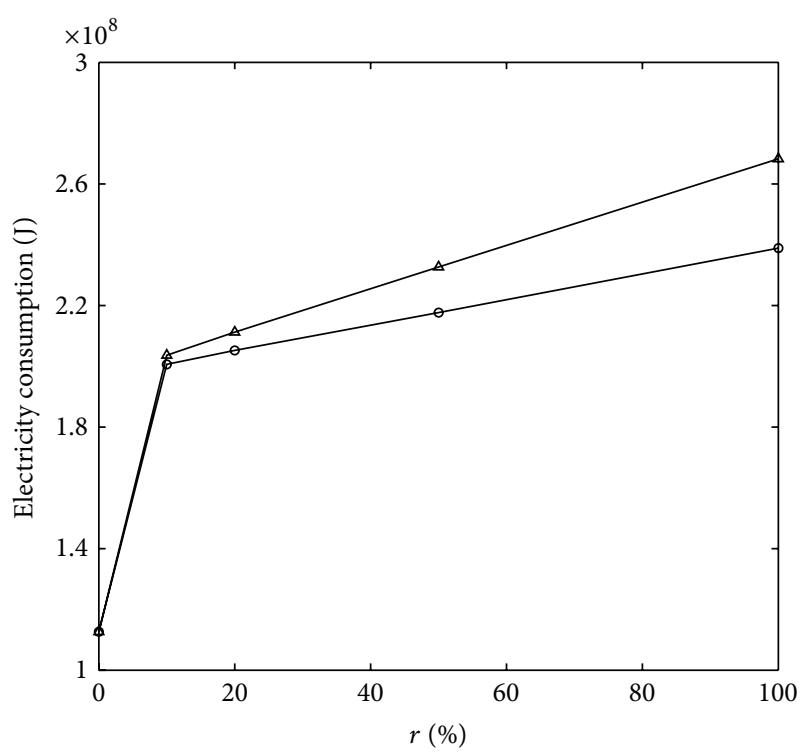

(a)

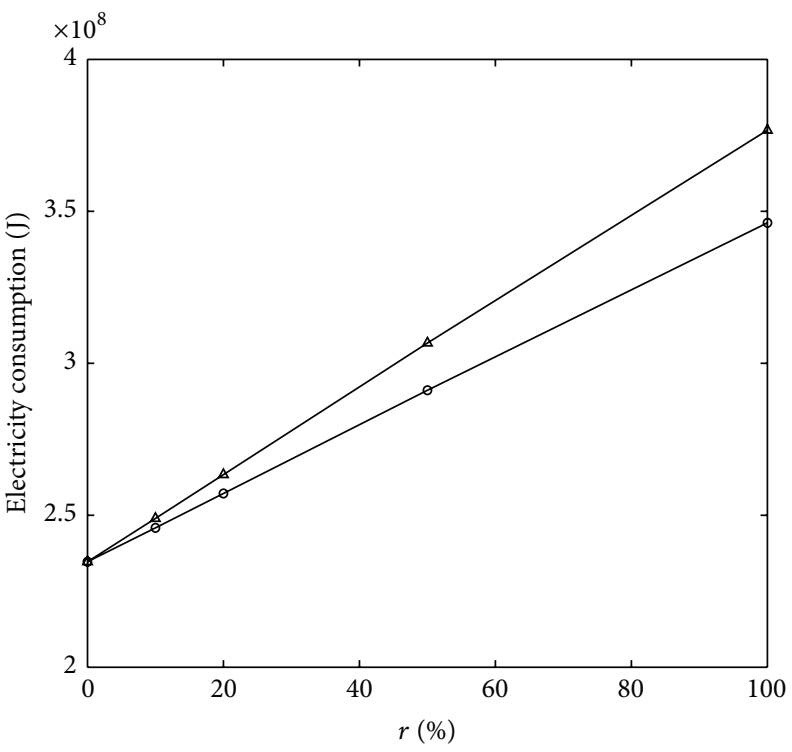

(b)

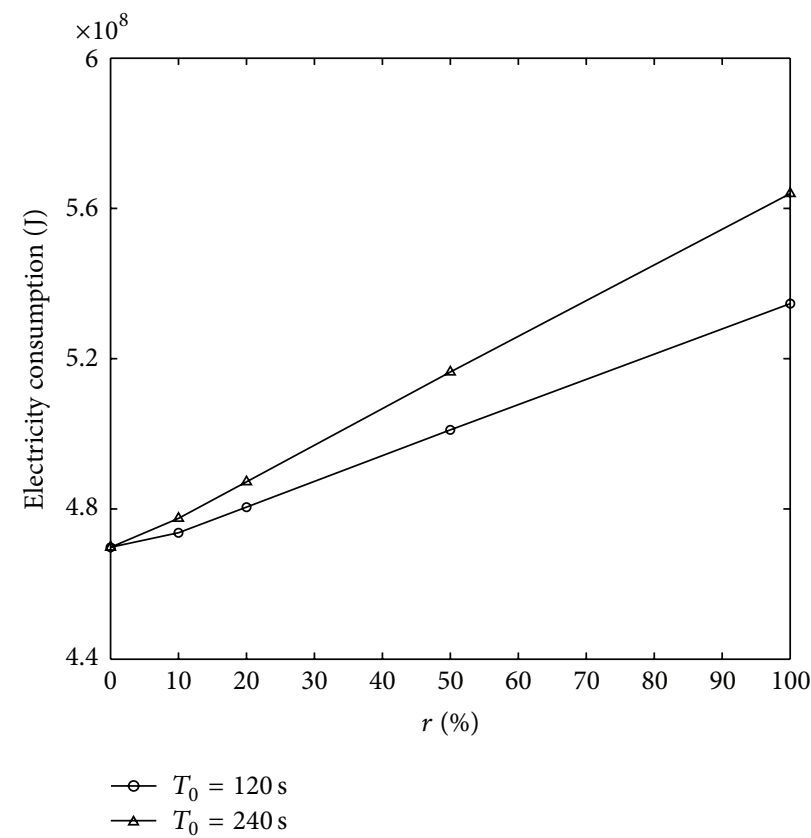

(c)

FIGURE 5: The total electricity consumed by all the vehicles under different conditions, where (a) $\Delta x_{0}=20 \mathrm{~m}$, (b) $\Delta x_{0}=40 \mathrm{~m}$, and (c) $\Delta x_{0}=80 \mathrm{~m}$.

(2) When the proportion of the electric vehicle that should exchange the battery is very low, the number of charging stations has little impacts on the total electricity consumed by each vehicle; when the proportion of the electric vehicle is relatively high, the number of charging stations has prominent impacts on the total electricity consumed by each vehicle; that is, the total electricity increases with $r$.

2.3. Case III. In this subsection, we study the impacts of the distance between the two charging stations on each vehicle's electricity consumption, where other parameters are the same as those used in Case I. The numerical results are shown in Figure 7. From this figure, we have the following.

(1) Figure 7 is qualitatively similar to Figure 6.

(2) When the proportion of the electric vehicle that should exchange the battery is very low, the distance between the two charging stations has little impacts on the total electricity consumed by each vehicle; when the proportion of the electric vehicle is relatively high, the distance between the two charging 


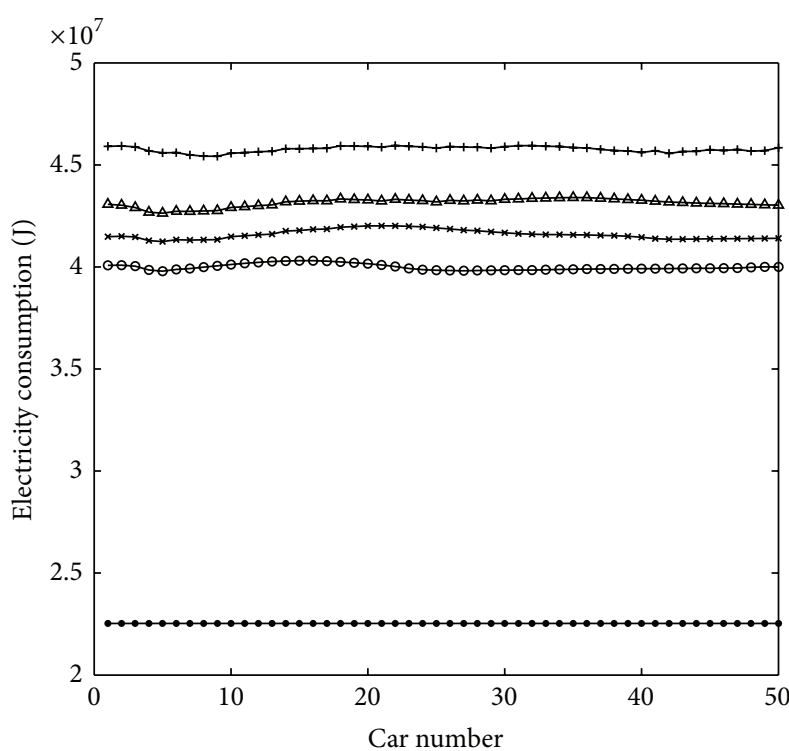

(a)

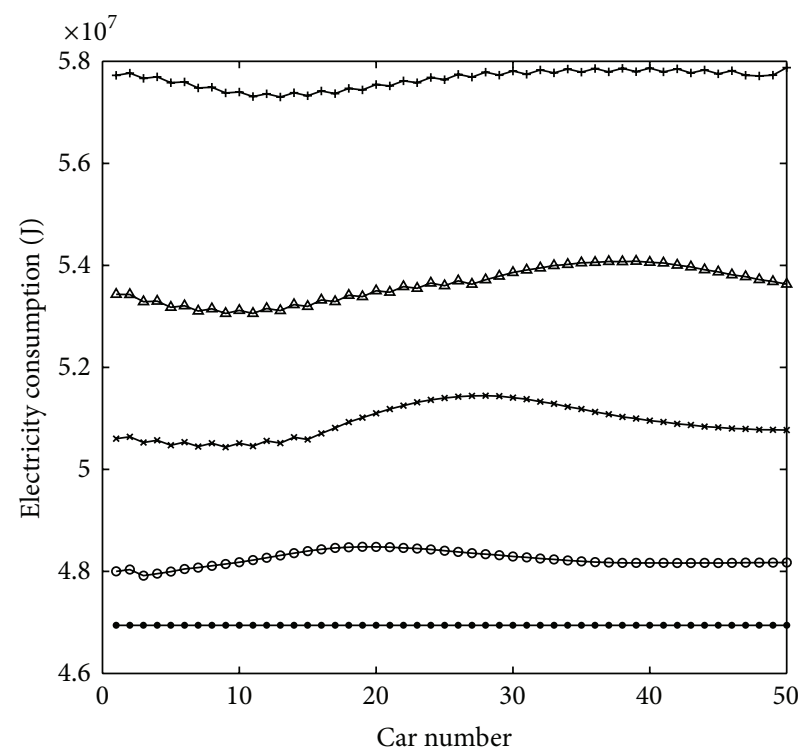

(b)

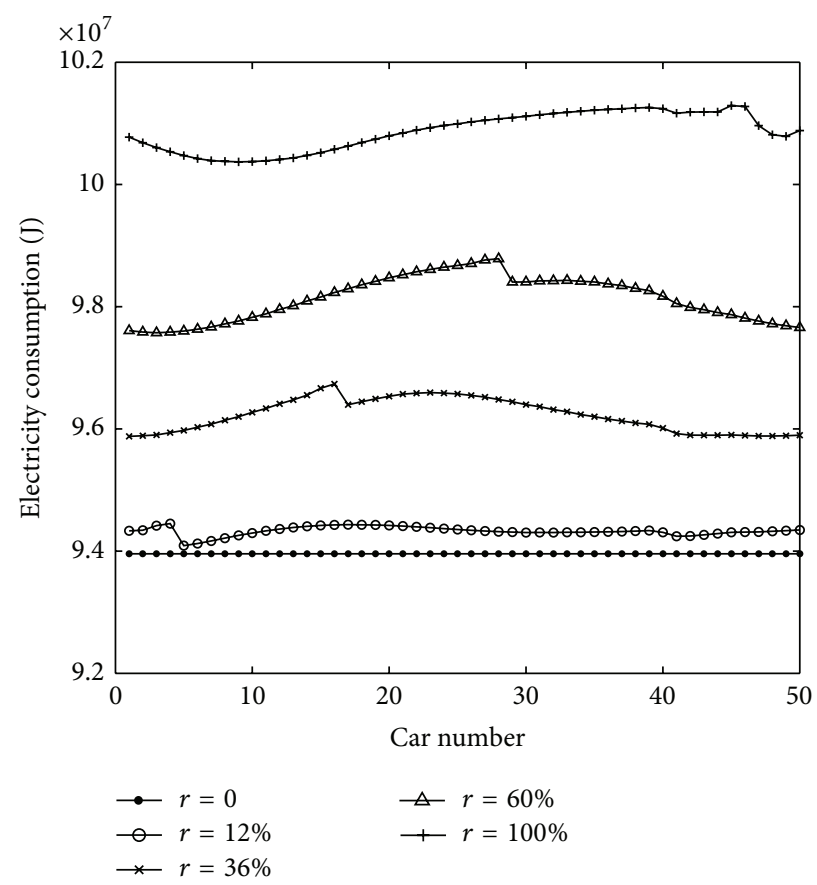

(c)

Figure 6: The total electricity consumed by each vehicle when the distance between the two charging stations is $300 \mathrm{~m}$, where (a) $\Delta x_{0}=20 \mathrm{~m}$, (b) $\Delta x_{0}=40 \mathrm{~m}$, and (c) $\Delta x_{0}=80 \mathrm{~m}$.

stations has prominent impacts on the total electricity consumed by each vehicle; that is, the total electricity decreases with the increasing of the distance.

\section{Conclusions}

In this paper, we use the car-following model to study the effects of exchanging battery on the electric vehicle's electricity consumption from the numerical perspective. The numerical results show that each vehicle's electricity consumption is enhanced because of exchanging the battery at the on-line charging station and that the increments are relevant to many factors; that is,

(1) the increments increase with the initial headway, the number of the charging stations, the number of the vehicles that should exchange the battery, and the time that the driver exchanges the battery;

(2) the increments decrease with the distance between two charging stations. 


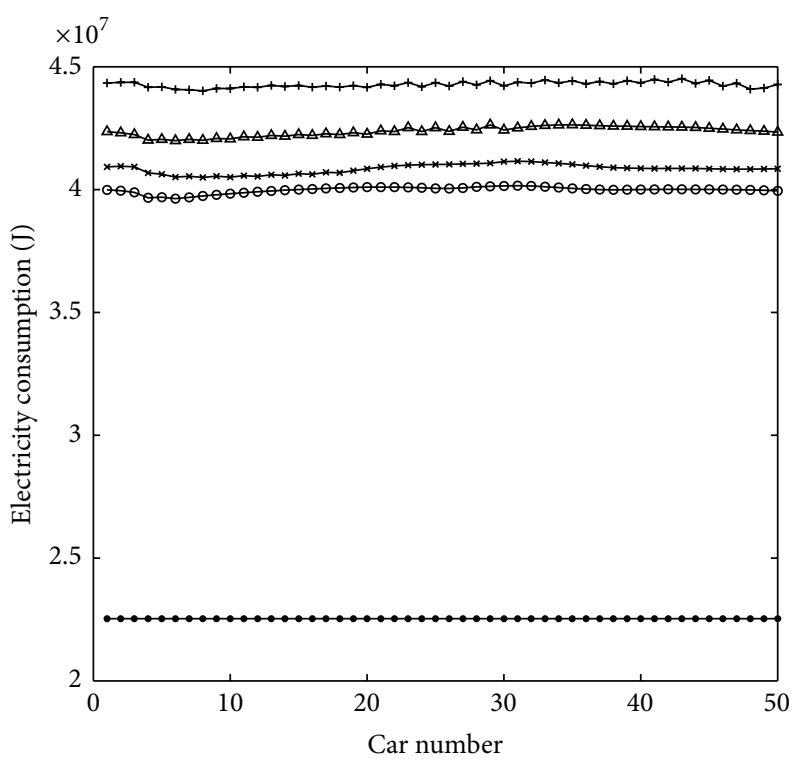

(a)

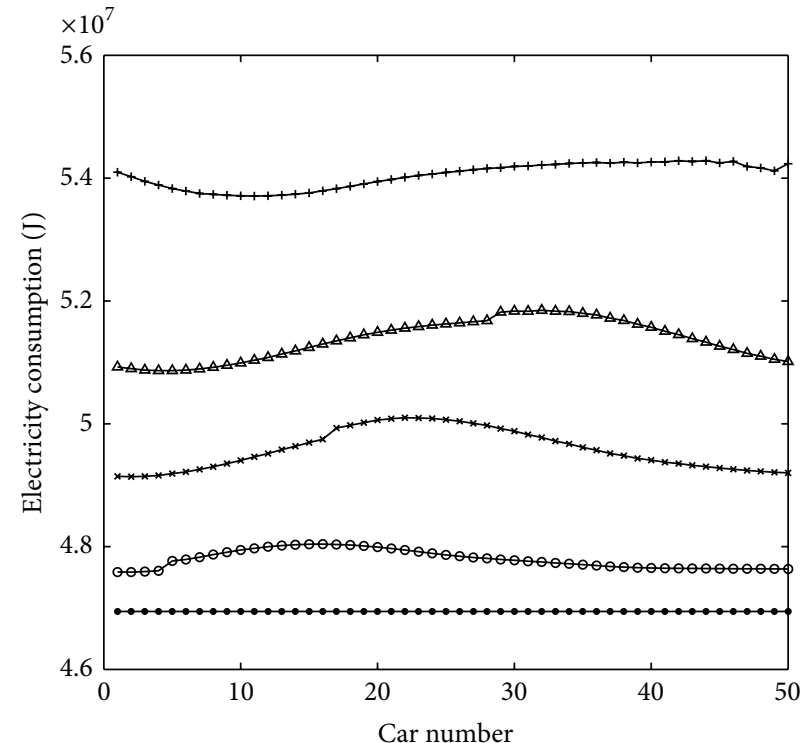

(b)

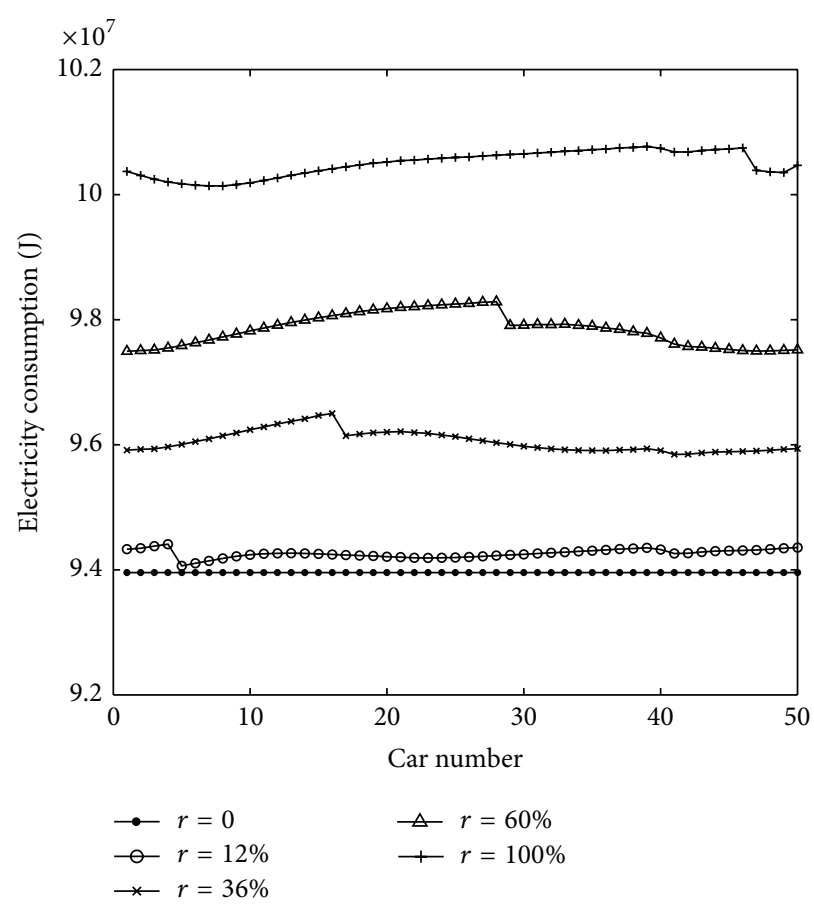

(c)

FIGURE 7: The total electricity consumed by each vehicle when the distance between the two charging stations is $500 \mathrm{~m}$, where (a) $\Delta x_{0}=20 \mathrm{~m}$, (b) $\Delta x_{0}=40 \mathrm{~m}$, and (c) $\Delta x_{0}=80 \mathrm{~m}$.

However, this paper has the following limitations.

(a) The parameters are not calibrated by empirical data.

(b) The road is a single-lane system, which is not accordant with the reality.

(c) The mode of the charging station is on-line; that is, we do not study the impacts of exchanging battery at the off-line charging station on each vehicle's electricity consumption. (d) We do not further study the effects of the numerical schemes on the numerical results (including the traffic phenomena, e.g., stop-and-go wave and travelling wave).

In view of the above limitations, we will use empirical data to study the effects of exchanging battery on the vehicle's electricity consumption (including the on-line charging station and off-line charging station) in the future. 


\section{Conflict of Interests}

The authors declare that there is no conflict of interests regarding the publication of this paper.

\section{Acknowledgment}

This paper has been supported by the National Natural Science Foundation of China (71271016).

\section{References}

[1] L. Ferreira, "Modelling urban fuel consumption: Some empirical evidence," Transportation Research A, vol. 19, no. 3, pp. 253268, 1985.

[2] K. Ahn, Microscopic fuel consumption and emission modeling [M.S. dissertation], Virginia Polytechnic Institute and State University, Blacksburg, Va, USA, 1998.

[3] H. Rakha, M. Van Aerde, K. Ahn, and A. A. Trani, "Requirements for evaluating traffic signal control impacts on energy and emissions based on instantaneous speed and acceleration measurements," Transportation Research Record, vol. 1738, pp. 56-67, 2000.

[4] D. G. Streets and S. T. Waldhoff, "Present and future emissions of air pollutants in China: $\mathrm{SO}_{2}, \mathrm{NO}_{x}$, and CO," Atmospheric Environment, vol. 34, no. 3, pp. 363-374, 2000.

[5] K. Ahn, H. Rakha, A. Trani, and M. Van Aerde, "Estimating vehicle fuel consumption and emissions based on instantaneous speed and acceleration levels," Journal of Transportation Engineering, vol. 128, no. 2, pp. 182-190, 2002.

[6] N. Davis, J. Lents, M. Osses, N. Nikkila, and M. Barth, "Development and application of an international vehicle emissions model," Transportation Research Record, no. 1939, pp. 157-165, 2005.

[7] H. Guo, Q.-Y. Zhang, Y. Shi, and D.-H. Wang, "Evaluation of the International Vehicle Emission (IVE) model with onroad remote sensing measurements," Journal of Environmental Sciences, vol. 19, no. 7, pp. 818-826, 2007.

[8] H. Yi, J. Hao, and X. Tang, "Atmospheric environmental protection in China: current status, developmental trend and research emphasis," Energy Policy, vol. 35, no. 2, pp. 907-915, 2007.

[9] C. X. Wu, G. Z. Zhao, and B. A. Ou, "A fuel economy optimization system with applications in vehicles with human drivers and autonomous vehicles," Transportation Research Part D: Transport and Environment, vol. 16, no. 7, pp. 515-524, 2011.

[10] S. Bai and S. M. Lukic, "Unified active filter and energy storage system for an MW electric vehicle charging station," IEEE Transactions on Power Electronics, vol. 28, no. 12, pp. 5793-5803, 2013.

[11] F. Guo, L. Fu, C.-H. Lin, C. Li, W. Choi, and J. Wang, "Development of an $85-\mathrm{kW}$ bidirectional quasi-Z-source inverter with DC-link feed-forward compensation for electric vehicle applications," IEEE Transactions on Power Electronics, vol. 28, no. 12, pp. 5477-5488, 2013.

[12] R. Cipollone, D. Di Battista, M. Marchionni, and C. Villante, "Model based design and optimization of a fuel cell electric vehicle," in Proceedings of the 68th Conference of the Italian Thermal Machines Engineering Association (ATI '13), pp. 71-80, September 2013.
[13] A. Jarrett and I. Y. Kim, "Influence of operating conditions on the optimum design of electric vehicle battery cooling plates," Journal of Power Sources, vol. 245, pp. 644-655, 2014.

[14] S. Ge, L. Feng, H. Liu, and L. Wang, "Planning of charging stations considering traffic flow and capacity constraints of distribution network," Power System Technology, vol. 37, no. 3, pp. 582-589, 2013.

[15] N. Sathaye and S. Kelley, "An approach for the optimal planning of electric vehicle infrastructure for highway corridors," Transportation Research E: Logistics and Transportation Review, vol. 59, pp. 15-33, 2013.

[16] S. Yang, C. Deng, T. Tang, and Y. Qian, "Electric vehicle’s energy consumption of car-following models," Nonlinear Dynamics, vol. 71, no. 1-2, pp. 323-329, 2013.

[17] S. C. Yang, M. Li, T. Q. Tang, and Y. Lin, "An electric vehicle’s battery life model under car-following model," Measurement: Journal of the International Measurement Confederation, vol. 46, no. 10, pp. 4226-4231, 2013.

[18] S. C. Yang, M. Li, Y. Lin, and T. Q. Tang, "Electric vehicle’s electricity consumption on a road with different slope," Physica A: Statistical Mechanics and its Applications, vol. 402, pp. 41-48, 2014.

[19] D. Helbing and B. Tilch, "Generalized force model of traffic dynamics," Physical Review E: Statistical Physics, Plasmas, Fluids, and Related Interdisciplinary Topics, vol. 58, no. 1, pp. 133138, 1998.

[20] T. Tie-Qiao, H. Hai-Jun, S. C. Wong, and J. Rui, "A new carfollowing model with consideration of the traffic interruption probability," Chinese Physics B, vol. 18, no. 3, pp. 975-983, 2009.

[21] E. Mehrdad, Y. M. Gao, E. G. Sebastien, and E. Ali, Modern Electric, Hybrid Electric, and Fuel Cell Vehicles: Fundamentals, Theory, and Design, CRC Press, Boca Raton, Fla, USA, 2005.

[22] M. Zhou, Z. Gao, and H. Zhang, "Research on regenerative braking control strategy of hybrid electric vehicle," in Proceedings of the 6th International Forum on Strategic Technology (IFOST '11), pp. 300-303, August 2011. 


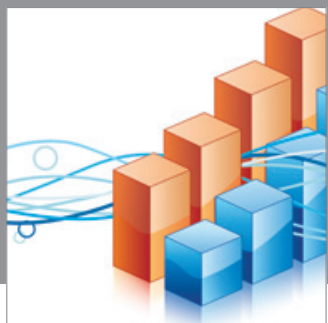

Advances in

Operations Research

mansans

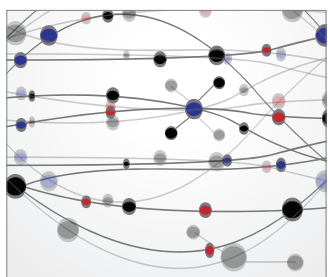

The Scientific World Journal
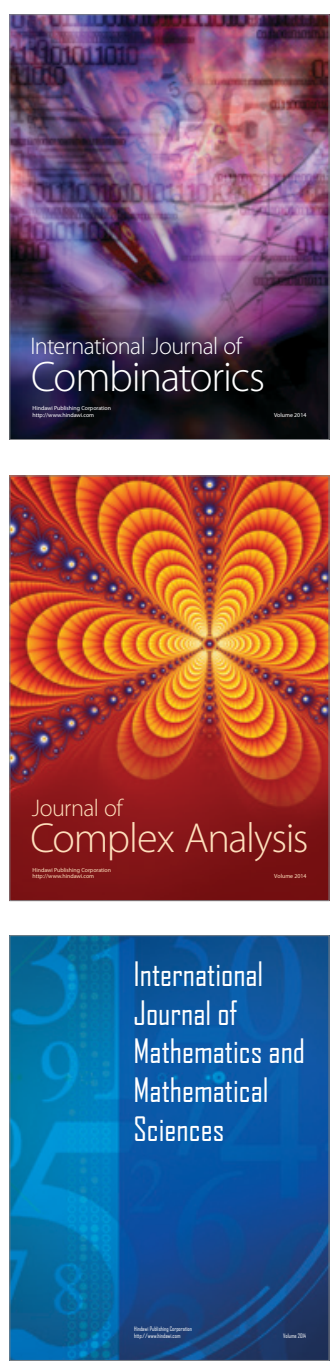
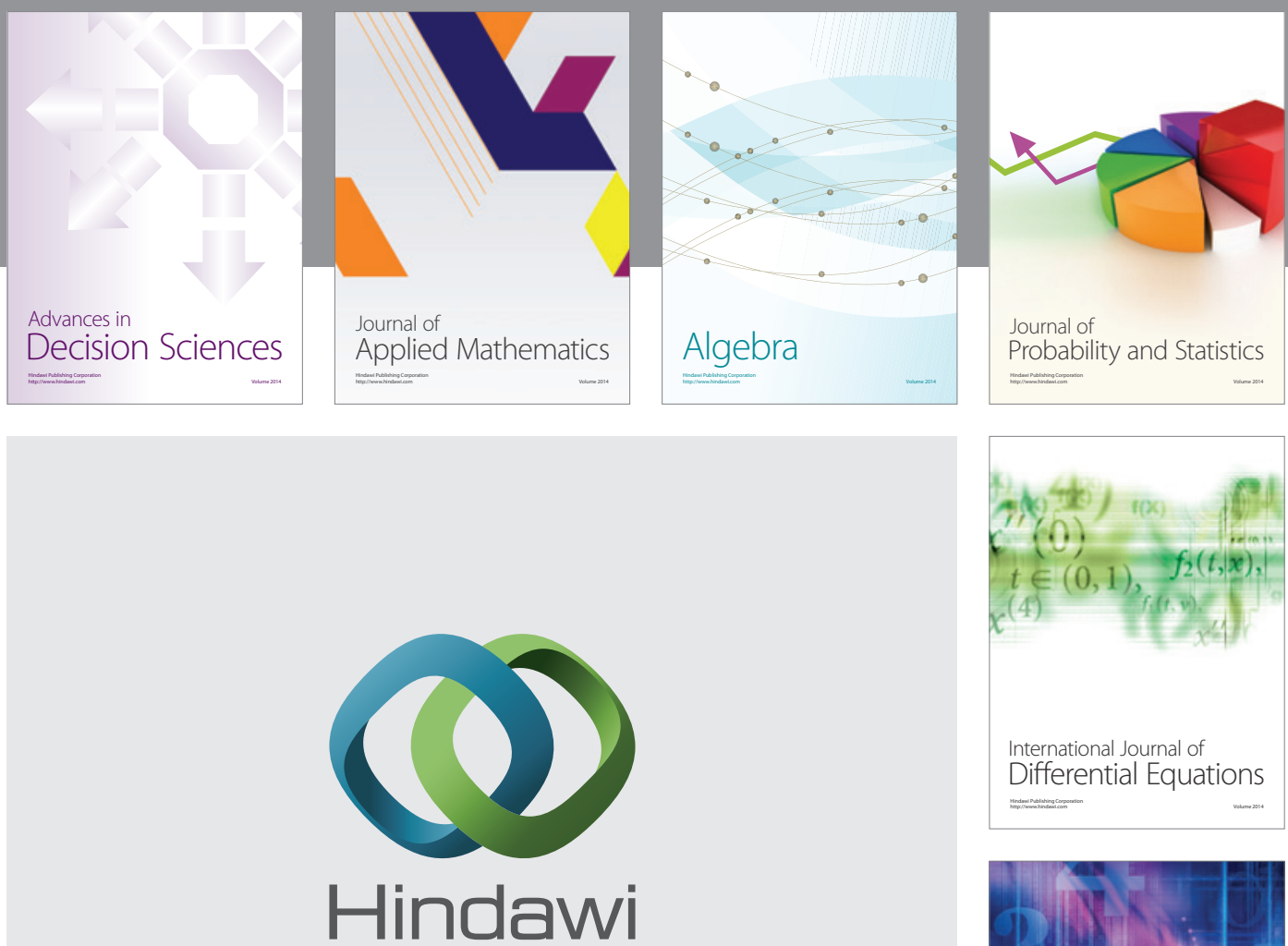

Submit your manuscripts at http://www.hindawi.com
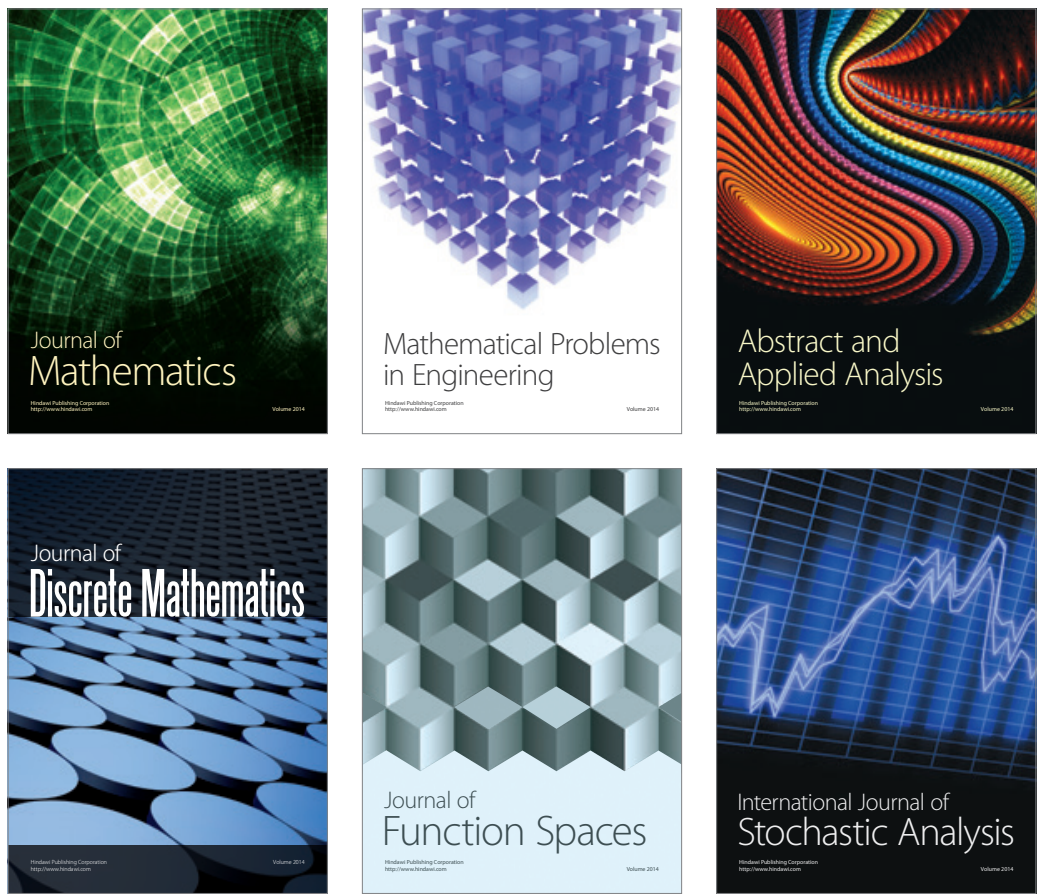

Journal of

Function Spaces

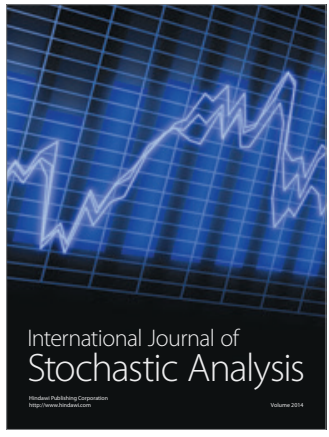

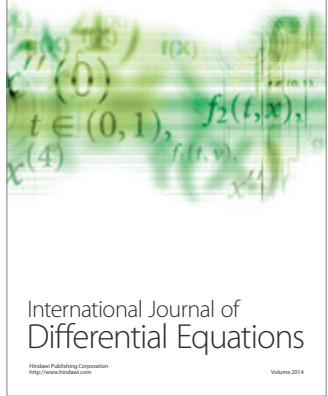
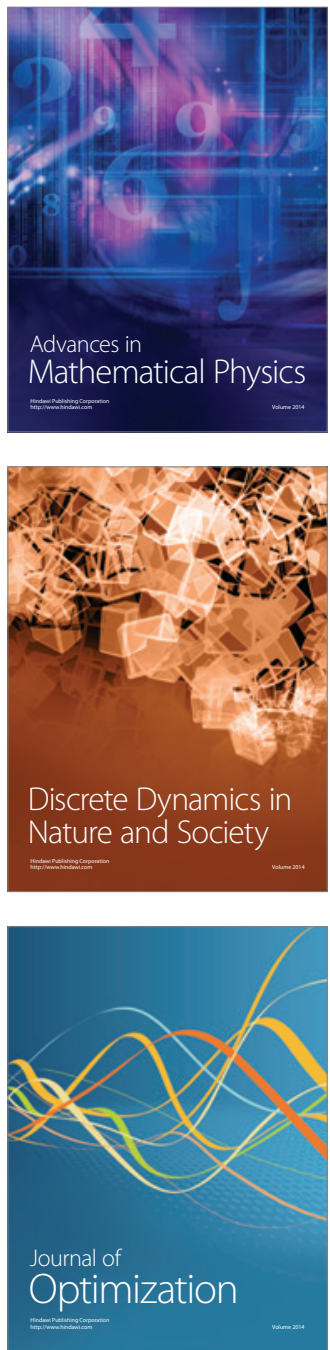